\title{
Цифровизация, автоматизация,
} идентификация и маркировка логистических объектов для решения задач клиентоориентированности

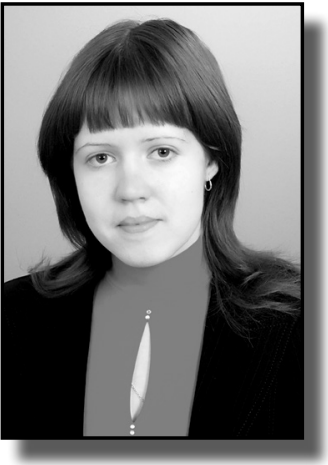

Оксана ПОКРОВСКАЯ

Покровская Оксана Дмитриевна - Петербургский государственный университет путей сообщения Императора Александра I (ПГУПС), Санкт-Петербург, Россия*.

Логистический сегмент деятельности железнодорожных холдинговых компаний в условиях информатизации и цифровизации транспорта переживает период динамичного развития, требующего существенных улучшений технологий, процессов и процедур.

Целью данного исследования является поиск оптимальных решений в сфере автоматизации процедур идентификации, маркировки и проектирования железнодорожных логистических объектов. Использовались инструменты статистического, системного, экономического анализа, компьютерного моделирования.

Представлены результаты разработки предложений по автоматизации, идентификации, маркировке и проектированию железнодорожных логистических объектов для унификации и упрощения принятия технико-эксплуатационных и экономических решений. Их реализация позволит решать целый комплекс задач управле- ния объектами терминально-складской инфраструктуры, а также будет способствовать расширению клиентской базы железнодорожных компаний, в рассмотренном случае - ОАО «РЖД», за счёт повышения доступности, простоты и клиентоориентированности информации о логистических объектах.

Разработана концепция автоматизированной системы управления терминальной сетью железнодорожного транспорта. Программные продукты обеспечат возможность расчёта ключевых параметров оценки, инвентаризации, контроля и рекламы логистических объектов. Возможно её применение в качестве основы для рекламы при формировании гибких коммерческих предложений. Внедрение концепции и сопровождающих её информационных решений позволит сформировать единую клиентоориентированную информационную среду и достичь 4-5 уровня логистического провайдинга.

Ключевые слова: железная дорога, железнодорожный бизнес, цифровая железная дорога, транспортно-логистическая деятельность, клиентоориентированность, идентификация, маркировка, логистический объект, терминальная сеть.

*Информация об авторе:

Покровская Оксана Дмитриевна - доктор технических наук, профессор кафедры

железнодорожных станций и узлов Петербургского государственного университета путей сообщения Императора Александра I (ПГУПС), Санкт-Петербург, Россия, insight1986@inbox.ru.

Статья поступила в редакцию 17.01.2019, принята к публикации 26.04.2019.

For the English text of the article please see p. 125.

Данное исследование выполнено в рамках гранта ОАО “РЖД» на развитие научнопедагогических школ в сфере железнодорожного транспорта (протокол от 07.09.2017 г. № 36 пр, утв. Президентом ОАО «РЖД» О. В. Белозеровым 11.10.2017 г.). 
$\mathbf{K}$ рупнейшие транспортные компании мира трансформируются в транспортно-логистические холдинги. Логистический сегмент становится важным ресурсом повышения эффективности их деятельности. Успешным примером организации транспортно-логистической деятельности является опыт железнодорожных холдинговых компаний «Дойче Бан» (DB), ОАО «РЖД».

Вместе с тем данное направление деятельности в условиях информатизации и цифровизации экономики и транспорта, внедрения новых технологий обработки информации, перехода взаимоотношений поставщиков услуг и клиентов в информационное пространство находится в динамичном развитии, требующем непрестанного поиска новых методов совершенствования деятельности, технологий, процессов и процедур, позволяющих добиться существенных улучшений.

Целью данного исследования является автоматизация процедур идентификации, маркировки и проектирования железнодорожных логистических объектов для унификации и упрощения принятия техникоэксплуатационных и экономических решений при управлении объектами терминально-складской инфраструктуры, а также для расширения клиентской базы железнодорожных компаний (на примере ОАО «РЖД») за счёт повышения доступности, клиентоориентированности и простоты «подачи» информации об объектах терминально-складской инфраструктуры.

При проработке предложений применительно к деятельности ОАО «РЖД» учитывались приоритеты, указанные в [1, 2], а также в комплексном проекте «Цифровая железная дорога» [3].

Основные задачи, решаемые исследованием:

1) сформулировать концепцию и модульную структуру автоматизированной системы управления терминальной сетью железнодорожного транспорта;

2) согласно политике клиентоориентированности, реализуемой холдингом «РЖД», разработать систему маркировки и идентификации логистических объектов железнодорожного транспорта, понятную каждому участнику перевозочного процесca;
3) разработать программное обеспечение, в котором автоматизированы изложенные методики идентификации, маркировки и принимаемые по ним решения.

Реализация предложений позволила бы железнодорожной компании, в нашем случае - ОАО «РЖД», добиться целевого состояния, при котором были бы возможны:

- «выдача» клиентам в максимально сконцентрированном и ёмком виде параметров логистических объектов, значимых при заказе логистического сервиса;

- немедленное применение предложения как маркетинговой рекомендации в рекламных кампаниях, а также структурами железнодорожной компании при выработке гибких коммерческих предложений;

- подготовка «цифровой платформы» [3] и, в случае ОАО «РЖД», «условий для трансформации... в статус логистического провайдера 4 уровня» [1];

- увеличение протяжённости и глубины контролируемых компанией логистических цепей (не только «от станции до станции», но «от клиента до клиента»);

- полная автоматизация расчётных и методических процедур;

- рост «тотальной управляемости объектов терминально-складской инфраструктуры» [2], возможности оценки их деятельности, инвентаризации и отслеживания текущих параметров в режиме реального времени;

- простота и удобство применения в современных условиях ведения транспортно-логистического бизнеса;

- качественный тотальный контроль за логистическими объектами, и, как следствие, за всеми логистическими цепями, выстраиваемыми холдингом при организации перевозок грузов;

- расширение клиентской базы за счёт информативности и простоты сведений о логистических объектах;

- «рост инвестиционной привлекательности как работающих на опорной железнодорожной сети логистических объектов, так и проектов строительства и поэтапного развития терминально-складской инфраструктуры высокого качества, «тяготеющей» к грузовым железнодорожным стан- 
циям» (согласно приоритетам, указанным В [1, 2]);

- реализация «цифровой трансформации» терминально-логистической деятельности компании путём «создания единой информационной среды» [3] для взаимодействия железнодорожного транспорта с клиентами и ведения единой базы данных о логистических объектах, упрощения процедур контроля, учёта и оценки деятельности железных дорог [4, с. 25];

- повышение конкурентоспособности предоставляемых ОАО «РЖД» терминально-логистических услуг в целом [5, c. 159].

В ходе исследования использовались общенаучные методы, инструменты статистического, системного, экономического анализа, компьютерного моделирования, программные средства.

\section{РЕЗУЛЬТАТЫ}

\section{Терминология}

Введём ряд определений, которыми будем оперировать.

Терминальной сетью будем считать «...coвокупность логистических объектов различного функционального типа и соединяющих их транспортных участков, которые обслуживаются унимодально или мультимодально, для рациональной организации процессов грузопереработки, перевозки и повышения добавленной стоимости товаров при доставке от клиента-грузоотправителя к клиенту-грузополучателю».

Логистические объекты - это «...объекты транспортно-складской инфраструктуры, которые по совокупности признаков сконцентрированы в пространственно определённом географическом районе и физически выполняющие широкий ассортимент операций комплексного терминально-логистического обслуживания различных клиентов и их грузов в системах доставки от начального грузоотправителя до конечного грузополучателя» [6, с. 70].

В качестве железнодорожного логистического объекта рассматривается объект терминально-складской инфраструктуры железнодорожного транспорта, который реализует функции узлового элемента терминальной сети как логистической системы и обеспечивает техническую и инфраструктурную поддержку при физическом выполнении различных услуг (погрузки, выгрузки, хранения, распределения грузов, доведение грузов до конечного потребителя) при взаимодействии с другими участниками процесса перевозок [7, с. 18].

Клиентоориентированные решения для терминально-логистической деятельности железнодорожной компании: идентификация и маркировка логистических объектов

Вносимые предложения, которые имеют во многом универсальный характер в отношении железнодорожных холдинговых компаний, в силу необходимости демонстрации их комплексного, системного характера, учитывающего специфику деятельности в конкретных рыночных условиях, рассматриваются применительно к ОАО «РЖД».

В первую очередь, предлагается применить принципы клиентоориентированности в информации о терминально-складских объектах холдинга, спрос на услуги которых сегодня устойчиво растёт. К сожалению, ОАО «РЖД» теряет потенциальных клиентов, которые «уходят» на приватные логистические объекты. Во многом такая ситуация «оттока» высокодоходных грузов с мест общего пользования обусловлена низкой клиентоориентированностью сведений о логистических объектах железных дорог и их функционале. Это не позволяет клиентам иметь полную информацию для принятия решений и существенно снижает доступность сведений о логистических объектах и о комплексном транспортнологистическом сервисе холдинга в целом.

При этом общеизвестно, что основой клиентоориентированного сервиса является его доступность, гибкость, информативность и удобство, а также достаточный уровень «осведомлённости» клиентов о реализуемых услугах. Упрощение и «цифровизация» отношений с клиентами рассматривается с позиций организации социально-экономического и технологического процесса создания ценности для ОАО «РЖД» как поставщика высококачественных логистических услуг.

Требуется максимальное обновление и визуализация сведений о логистических объектах. Сделать это возможно с помощью маркировки, нумерации (кода), «класса» для каждого логистического объекта

- МИР ТРАНСПОРТА, ТОМ 17 , № 4, С. 112-135 (2019) 


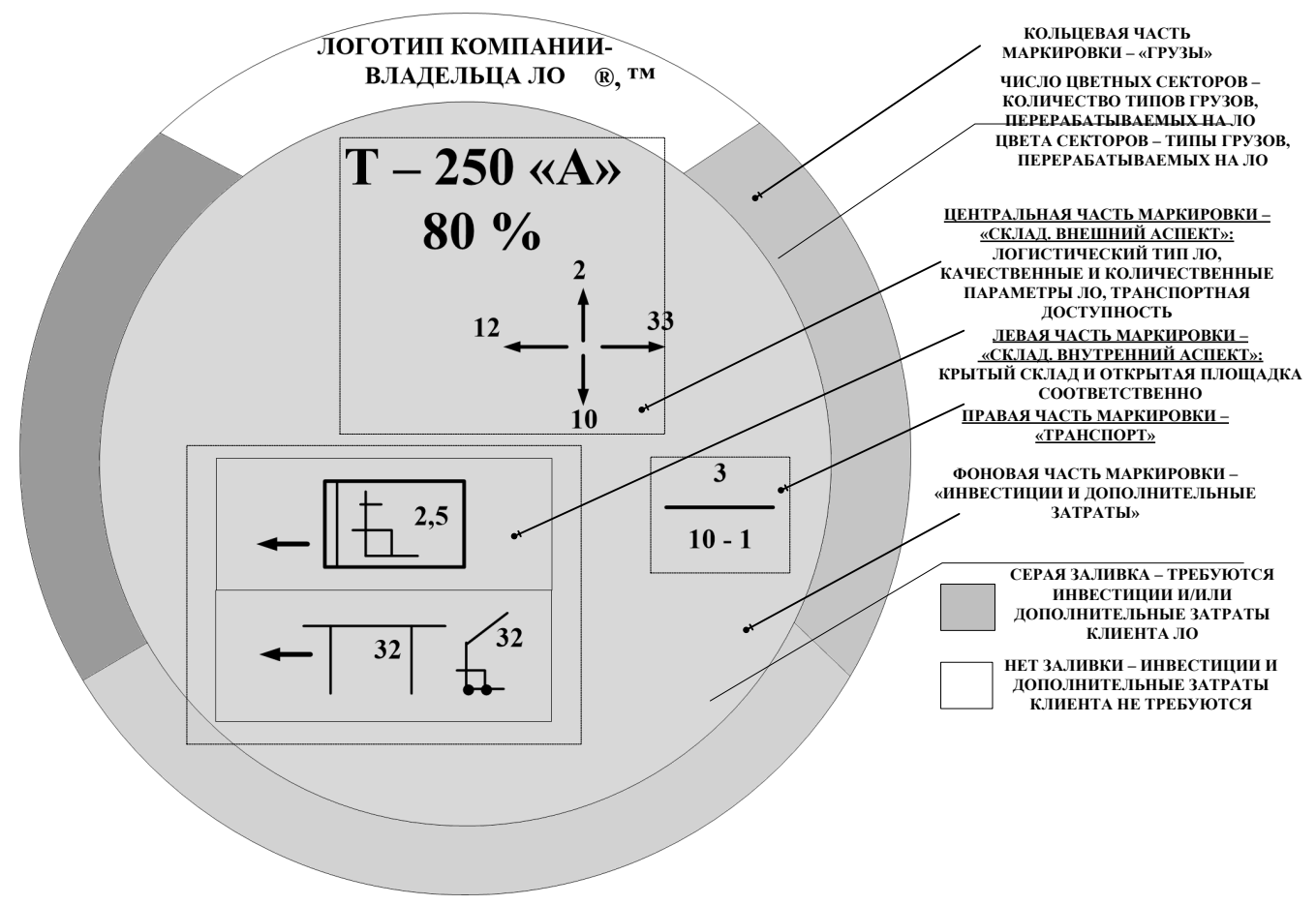

Рис. 1. Состав маркировочного знака логистического объекта.

с полным информационным покрытием. В современных условиях транспортно-логистического рынка становится необходимым переход «на общий язык» с клиентами. Например, в фармацевтической промышленности «ацетилсалициловая кислота» имеет более простое, потребительское название - «аспирин».

В частности, предложено закрепить за каждой железнодорожной станцией, открытой для грузовых операций, логистический класс, индивидуальный идентификационный номер и маркировочный знак. Такая система обозначений даст клиентам ключевую информацию о логистическом сервисе, предоставляемом каждым логистическим объектом - складом, терминальноскладским комплексом и прочими структурами, имеющимися на станции.

Логистический класс логистического объекта железных дорог представляет собой арабскую цифру от 1 до 9, определённую по балльной методике экспертным путём по всем логистическим функциям и операциям, выполняемым на станции, с учётом их комплексности. Логистический класс станции должен присваиваться экспертным путём (коммерческо-ревизионной службой, независимыми экспертами, клиентами) по балльной методике и размещаться в общем доступе.

Предлагаемый «логистический класс», в отличие от общепринятой системы классности и кодирования объектов станций [8-11], отражает функциональные и технико-технологические особенности терминально-складской инфраструктуры, расположенной на станции, а также ассортимент транспортного, складского и комплексного логистического сервиса. Иными словами, логистический класс напрямую связан с параметрами, максимально значимыми для клиента холдинга при принятии решения о пользовании услугами того или иного логистического объекта [12, c. 117].

Маркировочный знак логистического объекта - это краткая, но содержательная надпись, по которой легко определяется классность объекта (это полезно для арендаторов, несведущих в классности логистической инфраструктуры). Для составления маркировочного знака в реальных условиях ведения бизнеса автором была разработана автоматизированная программа.

Можно полагать, что на цветовом фоне удобно наносить надписи непосредственно на фасадах складских помещений, а также 
Рис. 2. Обозначения в центральной части маркировки.

использовать совместно с номером идентификации, в том числе - в рекламных целях. Маркировка позволит владельцу терминально-складской инфраструктуры (холдингу «РЖД») сэкономить на рекламе - увидев и прочитав её, клиент «найдёт» объекты самостоятельно.

На рис. 1 показан типичный состав такого маркировочного знака.

Маркировка логистического объекта в общем случае состоит из пяти зон (надписей):

Часть 1. «Грузы». Число цветных секторов указывает на число грузов, которые может перерабатывать данный логистический объект. Цвет каждого сектора указывает на тип груза.

Часть 2. «Склад». Т - транспортный терминал; 250 - общая полезная площадь хранения грузов на логистическом объекте, кв. м; А - классность складских зданий на ЛО, класс «А»; 80 \% - «покрытие» стандартных транспортно-складских услуг дополнительным логистическим обслуживанием, в \%. На рис. 2 описаны прочие обозначения части 2 маркировки.

Часть 3. «Склад (Технико-компоновочное решение)»: указатель типа примыкания железнодорожного пути к крытому складскому комплексу на логистическом объекте; указатель типа применяемого на крытых складах логистического объекта (вверху) стеллажного оборудования; указатель типа применяемого на логистическом объекте внутрискладского погрузочно-разгрузочного оборудования. На маркировке изображается компоновка крытых складов и открытых площадок. В случае, если внутри крытых складов для однотипных грузов применяется несколько типов оборудования, указывается только один, преимущественный, тип. Также приводятся: указатель типа открытой площадки (внизу); указатель полезной грузоподъёмности используемого погрузочно-разгрузочного оборудования логистического объекта на открытых площадках.
Часть 4. «Транспорт». 3 - средняя продолжительность оборота вагона в логистическом объекте, час; 10 - число вагонов в одной характерной подаче, вагонов; 1 интервал подач, час.

Часть 5. «Инвестиции». Есть заливка требуются дополнительные инвестиции (затраты клиента), нет заливки - не требуются. «Логотип» компании-владельца логистического объекта является дополнительной надписью и может отсутствовать. Условно маркировочный знак можно разделить на пять частей: «фоновая» (ч. 5), «кольцевая» (ч. 1), «центральная» (ч. 2), «левая» (ч. 3) и «Правая» (ч. 4). Преимущественно используются натуральные показатели, наиболее удобные для клиента (по материалам «Логистического руководства» $[13$, с. 98]).

Идентификационный номер представляет собой гибкое актуальное коммерческое предложение для клиента, которое может быть реализовано в нескольких вариантах. Два варианта представления идентификационных номеров даны в развёрнутом для владельца (вариант 1, «расширенный») и в кратком клиентском виде (вариант 2, «Клиентский»). При составлении системы идентификационной нумерации использовались результаты, полученные в исследованиях профессорами Маликовым О. Б. [14], Куренковым П. В. и другими исследователями [15-19], а также в ранее опубликованных работах автора [20-27].

\section{Вариант 1}

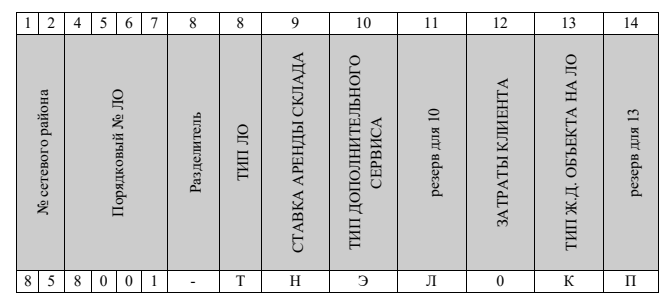

где - для варианта «расширенный»:

Часть 1. «Сетевой район» (две позиции). 85 - номер сетевого района, в соответствии с единой сетевой разметкой. 
Часть 2. «Номер объекта» (4 позиции). 8001 - порядковый номер объекта в сетевом районе. «Разделитель» (1 позиция).

Часть 3. «Тип ЛО» (одна позиция). Т транспортный терминал (тип логистического объекта по авторской классификации: $\mathrm{P}$ - грузовой район, грузовая площадка, С - склад, терминально-складской комплекс, Ц - распределительный центр, Л - логистический центр, У - транспортно-логистический узел, М - мультимодальный транспортно-логистический центр; Н - буква латинского алфавита, по интервалу стоимости).

Часть 4. «Ставка аренды» (одна позиция). Ставка хранения на ЛО, евро/1 единица хранения в сутки (1 паллета, 1 контейнер, 1 тонна груза) - 31-50 евро/Кв. метр.

Часть 5. «Дополнительный сервис» (одна позиция). Э, Л - указание на выполняемые на логистическом объекте услуги: Э - экспедирование, Л - лизинг и др. «Резерв» (для части 5 , одна позиция).

Часть 6. «Затраты клиента» (одна позиция). Указание на необходимость дополнительных затрат (на аренду грузовой техники, оформление документации, персонал, ремонт оборудования и здания, собственно оборудование...): 0 - Нет (1 - есть).

Часть 7. «Тип железнодорожного ЛО» (для части 7, одна позиция): К, П - в соответствии с инструкцией по кодированию объектов станций и грузов на железных дорогах, расширенный ещё тремя видами объектов; с учётом: типа складирования, логистической роли объекта, типа груза ( $\mathrm{K}$ - контейнерный пункт, П - пункт перегрузки/перевалки) (согласно проекту «Логистического руководства железнодорожного транспорта», разработанного автоpoм, [13, c. 88-98]).

Вариант 2

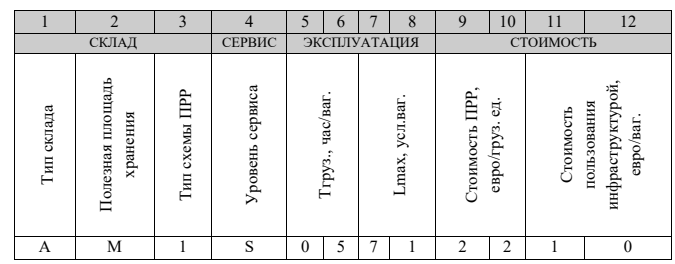

где - для варианта «клиентский»:

Часть 1. «Склад». 1 - условный измеритель, типология складов на ЛО (превалирующий тип) по международной классификации складских зданий и помещений, буква латинского алфавита A, B, C, D (по известной международной классификации компании Knight Frank); 2 - условный измеритель, общая полезная площадь хранения на ЛО: М - Medium (1400-1799 Кв. м); 3 - условный измеритель, компоновка погрузочно-разгрузочной схемы (подход железнодорожного пути/путей, тип используемого/используемых ПРМ), 1 с использованием козлового крана.

Часть 2. «Сервис». 4 - S - пакет сервиca (Small): стандартные услуги (погрузкавыгрузка, приём-выдача, оформление документации, хранение, услуги «от двери до двери», «последняя миля»).

Часть 3. «Эксплуатация». 5, 6 (две позиции) - натуральный измеритель, средняя продолжительность погрузки (выгрузки) одного вагона на ЛО, ч., 7, 8 (две позиции) - натуральный измеритель, максимальная длина состава, подаваемого под погрузкувыгрузку, условных вагонов.

Часть 4. «Стоимость». 9, 10 (две позиции) - плата за выполнение погрузочновыгрузочных работ с 1 единицей груза (паллета, тонна, контейнер), евро/ед.; 11, 12 (две позиции) - плата за пользование инфраструктурой (аренда места), евро/ваг. (согласно проекту «Логистического руководства для железнодорожного транспорта», разработанного автором, [13, c. $79-88])$.

Тип складского помешения приводится согласно требованиям международных классификаций, например, [28-29]. Очевидно, что впоследствии для общесетевого применения потребуется создание базы данных идентификационных номеров и маркировочных знаков. Автором получены свидетельства Роспатента на программное обеспечение маркировки, идентификации и проектирования логистических объектов. Возможно создание также цифрового паспорта логистического объекта, вид которого дан на рис. 3.

\section{РЕАЛИЗАЦИЯ ПРИОРИТЕТОВ «ЦИФРОВОЙ ЖЕЛЕЗНОЙ ДОРОГИ" ПРИ УПРАВЛЕНИИ ДЕЯТЕЛЬНОСТЬЮ ЛОГИСТИЧЕСКИХ ОБЪЕКТОВ}

В связи с ростом потребностей клиентов и развитием IT-технологий политика ОАО «РЖД» нуждается в реформировании сво- 


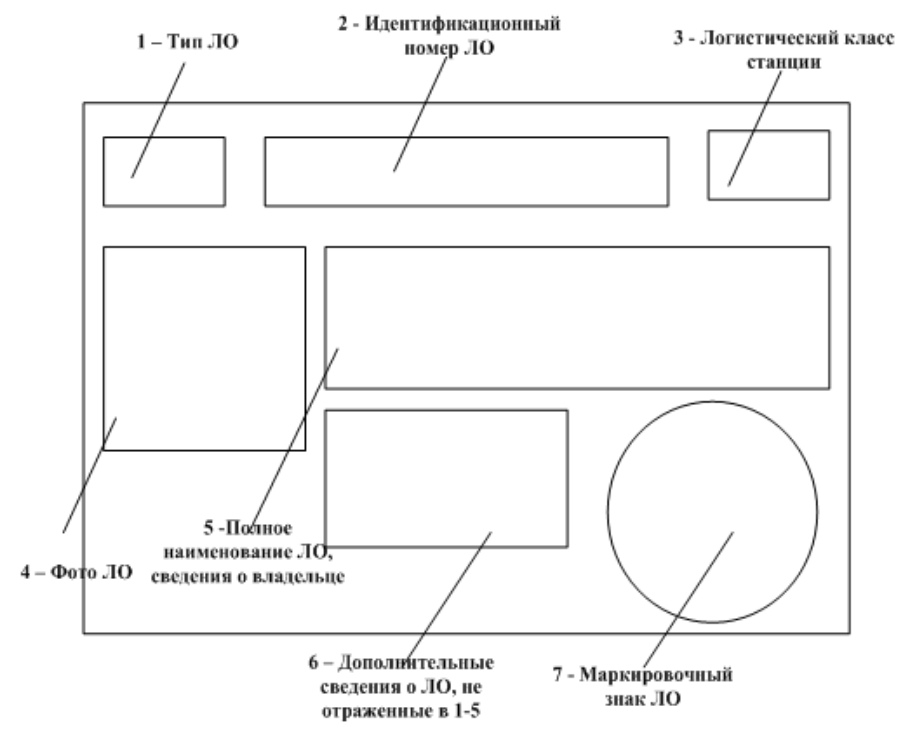

Рис. З. Структура электронного паспорта ЛО в едином информационном поле ОАО “РЖД”.

ей деятельности в направлении цифровизации и инновационного развития. В 2017 году холдинг «РЖД» в рамках участия в программе «Цифровая экономика» запустил проект «Цифровая железная дорога» по разработке и внедрению цифровых технологий в ключевые бизнес-процессы и услуги компании. Проект представляет собой совокупность «...информационных технологий, процессов и стандартов взаимодействия, соответствующих цифровой модели бизнеса» [3].

Концепция инновационного развития железнодорожного транспорта предполагает переход «от платформоцентрического подхода управления к сетецентрическому» - то есть, от развития информационных платформ и систем к их интеграции в единое информационное поле [30, 31]. Это позволит перевозчикам, грузоотправителям, грузополучателям, собственникам подвижного состава и инфраструктуры координировать действия и принимать оперативные решения на основе полной и достоверной информации о ходе процесса.

Сегодня компании холдинга «РЖД» обеспечивают комплексное логистическое обслуживание клиентов, включая обеспечение складского обслуживания, консалтинга, логистики, мультимодальных перевозок и др.

Для современной науки и практики очевидно, что цифровые сервисы - драй- веры мирового экономического роста. По оценке Глобального института McKinsey к 2025 г. увеличение ВВП Китая до $22 \%$, а США до $19 \%$ произойдёт за счёт Интернеттехнологий. При этом, как утверждают эксперты «Росбизнесконсалтинга», эффект цифровизации транспорта РФ увеличит ВВП к 2025 г. на 4,1-8,9 трлн руб., до 34 \% ожидаемого роста ВВП [33, с. 10].

Согласно [3], цифровые услуги - это «...комплекс организационно-технических и методологических мероприятий в сфере информационных технологий по предоставлению клиентам автоматизированной функциональности сервиса». Концепция направлена на создание для клиентов автоматизированного сервиса, с помощью которого заказ и оформление перевозок будет проще. Это позволит увеличить объёмы перевозок, а, следовательно, и доход от реализации цифрового «околотранспортного» сервиса.

Основные направления: создание единой дорожной карты на сети РЖД, «Интернета вещей», технологии больших данных, интеллектуальных систем, мобильных приложений. Известно, что достижение рентабельности за счёт ценовой политики не всегда возможно. Поэтому, помимо базовой услуги по перевозке, ОАО «РЖД» развивает дополнительный сервис как способ привлечения и удержания клиентов. 


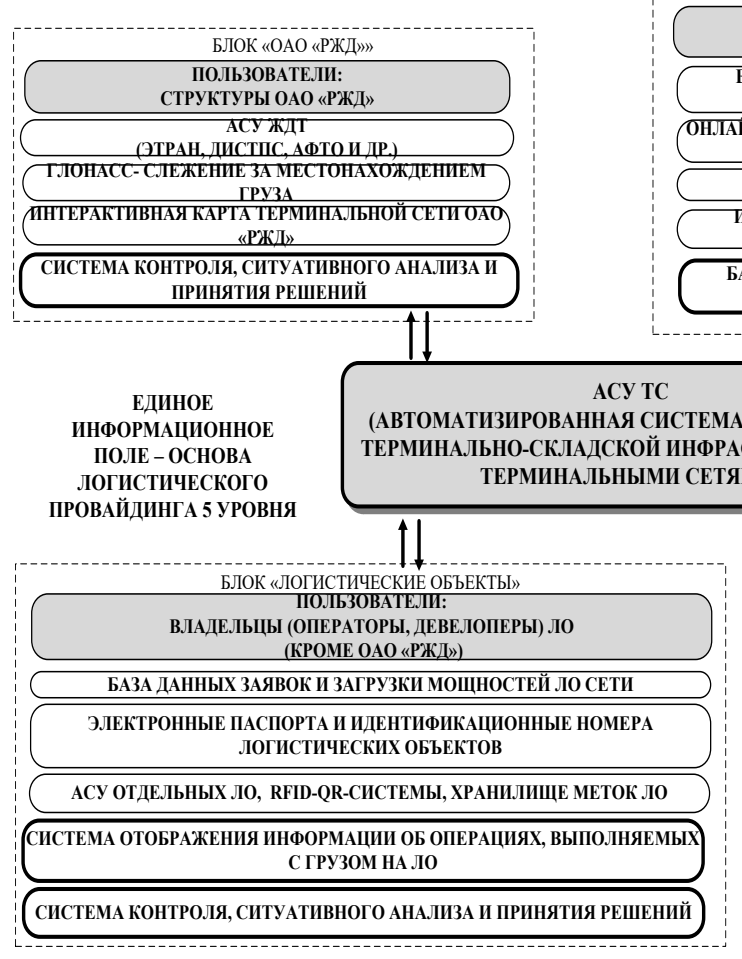

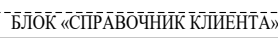

ПОЛЬЗОВАТЕЛИ:

КЛИЕНТЫ-ГРУЗОВЛАДЕЛЬЦЫ

БАЗЫ ДАННЫХ И САТЕЛЛИТЫ ПО ИДЕНТИФИКАЦИИ,

КЛАССИФИКАЦИИ И МАРКИРОВКЕ ЛО

ОНЛАЙН-ЗАЯВКА, ЛИЧНЫЙ КАБИНЕТ, ОНЛАЙН-ОТСЛЕЖИВАНИЕ ОПЕРАЦИЙ С ГРУЗОМ

ПРЕЙСКУРАНТЫ, ОНЛАЙН-КАЛЬКУЛЯТОР

АЦИОННО-СТТРАВОЧНАЯ СИСТЕМА
ХАРАКТЕРИСТИКИ ОБЪЕКТОВ)

БЗА ДАННЫХ ПО КЛИЕНТАМ, ЗАЯВКАМ, АКТУАЛЬНЫМ ПРЕДЛОЖЕНИЯМ

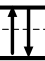

Рис. 4. Общая архитектура Автоматизированной системы управления «Терминальная сеть».

В программе клиентоориентированности есть элементы Концепции «Цифровая железная дорога». Приведём примеры: «обратная связь с клиентом»; «каталогизация услуг», «единая база данных «Интернет вещей» для обмена информацией между перевозчиком и клиентом»; «расширение географии перевозок»; «доступность информационных услуг и порталов»; «совершенствование систем слежения и контроля»; «комплексность услуг» (составлено по материалам [1-3]).

Для реализации основных направлений по созданию «Цифровой железной дороги» и внедрения принципов клиентоориентированности холдингом «РЖД» в 2018 г. создано ООО «Цифровая логистика» для разработки и реализации цифровых сервисов холдинга РЖД с использованием электронной торговой площадки «Грузовые перевозКИ».

Рассмотрим в свете реализуемой политики «Цифровизации» бизнеса проект автоматизированной системы управления «Терминальная сеть», которая может стать «цифровой платформой» для реализации терминально-логистической бизнес-активности ОАО «РЖД».

\section{АВТОМАТИЗИРОВАННАЯ СИСТЕМА УПРАВЛЕНИЯ «ТЕРМИНАЛЬНАЯ CETb"}

$A C У$ «Терминальная сеть» - это «цифровая платформа» для ведения терминальнологистического бизнеса холдингом «РЖД» «со скоростью клика», которая представляет собой общероссийскую сетевую базу данных (возможен формат «облака» или «сателлита» для известных систем, например, единой сетевой разметки и классности станций) как клиентоориентированный онлайн-сервис для заказчиков и поставщиков логистического сервиса.

Автором была разработана принципиальная структура такой единой системы управления логистическими объектами «Автоматизированная система управления «Терминальная сеть» (рис. 4).

Возможный модульный состав автоматизированной системы управления «Терминальная сеть» показан на рис. 5.

В развитие предложений по идентификации и маркировке логистических объектов возможно составление «интерактивной $\kappa a p m ы »$ работающих на опорной железнодорожной сети логистических объектов для учёта их текущего состояния, ключевых 


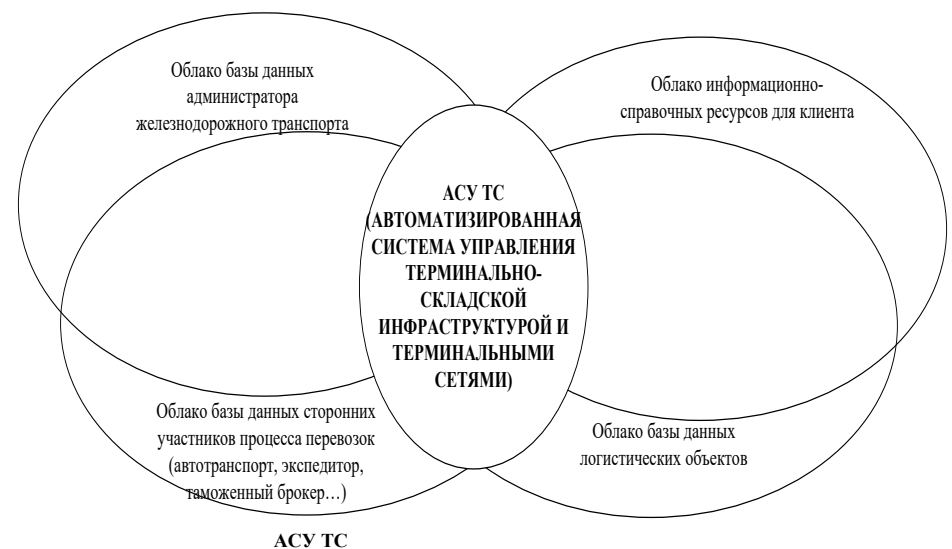

(АВТОМАТИЗИРОВАННАЯ СИСТЕМА УПРАВЛЕНИЯ ТЕРМИНАЛЬНО-СКЛАДСКОЙ ИНФРАСТРУКТУРОЙ И

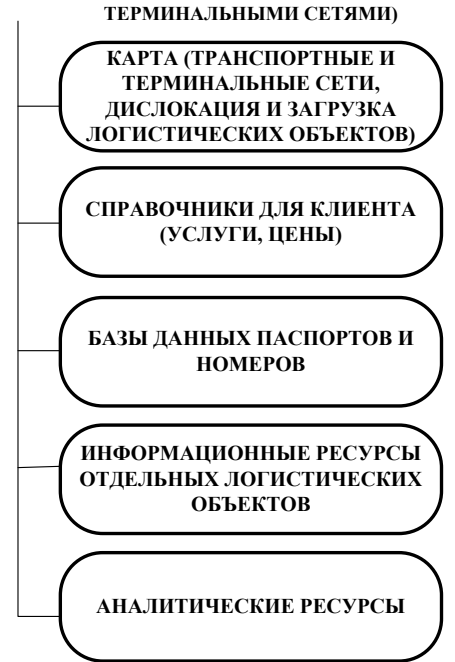

PEСУРСЫ:

КОЛЛЕКТИВНОГО ПОЛЬЗОВАНИЯ

коЛЛЕКТИВНОГО ПОЛЬЗОВАНИЯ

КОЛЛЕКТИВНОГО ПОЛЬЗОВАНИЯ

ТОЛЬКО ДЛЯ АДМИНИСТРАТОРА ОГРАНИЧЕННОГО ДОСТУПА

ОГРАНИЧЕННОГО ДОСТУПА

Рис. 5. Состав информационно-справочных и аналитических ресурсов Автоматизированной системь управления “Терминальная сеть» (сокращение: АСУ ТС - Автоматизированной системы управления “Терминальная сеть»).

параметров, а также их эффективной загрузки, мощности и визуализации их числа и дислокации на территории сетевых районов. Такая карта с «обратной связью» может быть полезна и при решении «вопросов этапного развития и/или проектирования терминальной сети ОАО «РЖД» (по приоритетам, указанным в [1-3]), а также при решениях об инвестировании объектов.

Предлагаемая автоматизированная система управления терминально-складской инфраструктурой и терминальной сетью ОАО «РЖД», интегрированная с объектами взаимодействия, позволит анализировать работу логистических объектов и всей сети, вести визуальный контроль оперативной обстановки по загрузке терминальных мощностей, обрабатывать заявки на логистический сервис «в одно окно».
Предпосылкой её создания следует считать веление времени: сегодня холдингу «РЖД» объективно необходим единый интерфейс, приемлемый для всех участников процесса перевозок. Всё это может и должно стать функциональным инструментом при решении проблем взаимодействия участников процесса перевозок и создать информационное обеспечение выхода ОАО «РЖД» на новый уровень логистического провайдинга (4-5 уровень логистики), предполагающий наличие единой электронной среды логистического оператора, сокращение областей видимости данных и снижение нагрузки на систему «электронная транспортная накладная» (ЭТРАН).

Можно полагать, что внедрение автоматизированной системы управления «Терминальная сеть» повысит эффективность 


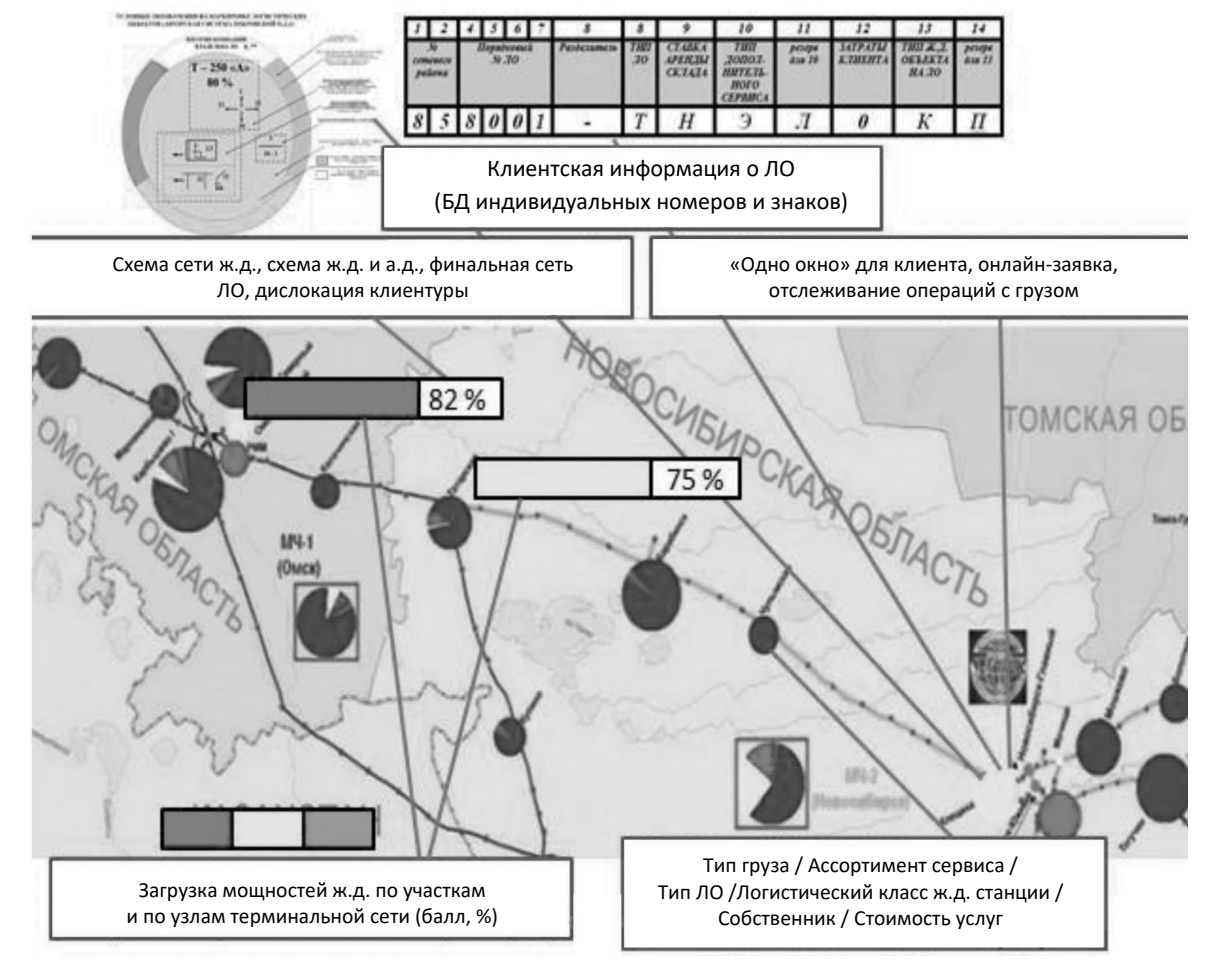

Рис. 6. Общий вид возможной интерактивной карты Автоматизированной системы управления “Терминальная сеть" (сокращения: ЛО - логистический объект, БД - база данных).

управленческих решений и ведения онлайнконтроля терминально-складской бизнесактивности холдинга «РЖД» в целом. В свою очередь, это обеспечит принятие адекватных решений по организации транспортно-логистических систем доставки грузов через железнодорожную терминальную сеть.

Состав интерактивной карты представлен на рис. 6.

В состав системы должны входить следующие блок-элементы: «Информационносправочные ресурсы» для клиента; «Системы управления», имеющие прямой доступ к автоматизированным системам управления железнодорожного транспорта и других участников процесса перевозок; «База данных ологистических объектах» (маркировочные знаки, идентификационные номера и электронные паспорта логистических объектов); «Интерактивная карта терминальной сети» ОАО «РЖД», отражающая существующее состояние и размещение логистических объектов (в том числе тяготеющих к сети железных дорог), визуализация её возможностей (техническая оснащённость, ключевые параметры, ассортимент логистического сервиса), её загрузки (пол- ноты использования), а также проекты перспективного развития с учётом капиталоёмкости и приоритетности реализации; «Другая информация» - для администраторов - представителей железнодорожного перевозчика, которые могут редактировать информацию о логистических объектах в режиме реального времени, реализуя принципы клиентоориентированности и работы «в одно окно».

Автоматизированная система управления «Терминальная сеть» должна обладать такими признаками, как:

- сетевой характер,

- единство управления и вертикальноинтегрированная структура,

- возможность просмотра и редактирования базы данных в режиме реального времени.

При этом её применение должно быть ориентировано на клиента для работы «в одно окно», а также на служебное применение в оперативных целях ОАО «РЖД» для анализа ситуации и корректировки сведений об объектах.

Для клиентов автоматизированная система управления «Терминальная сеть» позволит выбрать подходящий по парамет- 
рам и услугам терминально-складской объект и ту грузовую станцию, на которой он расположен. После возможно не только получение исчерпывающей информации о ЛО и оформление заказа, но и подбор пакета дополнительных услуг по комплексному логистическому «сопровождению» грузодвижения.

Для ОАО «РЖД» автоматизированная система управления «Терминальная сеть» позволит оценивать уровень логистического обслуживания как по всей протяжённости сети железных дорог, так и по её отдельным полигонам, а также планировать развитие собственной терминальной сети на основе автоматизированного расчёта логистических показателей.

Вышеизложенное позволяет полагать, что сформулированные в исследовании предложения соответствуют основным критериям, предъявляемым к свойствам предоставляемой клиенту информации, которые отражены в [30; 31, с. 11].

\section{ПРИМЕНИМОСТЬ РЕЗУЛЬТАТОВ И ПОТЕНЦИАЛЬНАЯ ЭФФЕКТИВНОСТЬ}

К основным результатам исследования можно отнести:

1) автоматизированные решения по идентификации, маркировке и проектированию железнодорожных логистических объектов для унификации и упрощения принятия технико-эксплуатационных и экономических решений;

2) концепцию формирования и структуры автоматизированной системы управления терминальной сетью железнодорожного транспорта.

По итогам проведённой работы подготовлен проект «Логистического руководства» для железнодорожного транспорта в виде монографии [13]. Проект:

1) включает методику расчёта и оценки логистических показателей работы терминально-складской инфраструктуры железнодорожного транспорта;

2) содержит типологию и параметрические ряды логистических объектов;

3) может использоваться как основа для государственного стандарта в сфере терминально-логистической деятельности и логистического нормирования на железнодорожном транспорте.
Таким образом, реализация внесённых предложений позволит превратить компании ОАО «РЖД» «упущенную» выгоду в реальную, равную не менее 133 млрд руб. в год. В работе [32, с. 450] установлено, что «упущенная» выгода ОАО «РЖД» от потери потенциальных клиентов, которые пользуются услугами приватных логистических объектов, не входящих в терминальноскладскую инфраструктуру холдинга, составляют не менее 133 млрд руб./год.

В России на сети железных дорог действуют порядка пяти тысяч различных по функционалу, типу и формату бизнеса логистических объектов, на инфраструктурной базе которых компания ОАО «РЖД» предоставляет широкий ассортимент терминально-логистических услуг [1]. Следует отметить, что в 2017 году доля таких услуг в портфеле холдинга «РЖД» составляла примерно $20 \%$ [2].

С одной стороны, холдинг «РЖД» разграничивает сферы деятельности и имеет два обособленных подразделения в своей структуре: по управлению перевозками и по управлению терминально-складским комплексом. С другой, стремится обеспечить комплексное обслуживание грузов и грузовладельцев.

При трансформации компании «РЖД» из перевозочной и инфраструктурной в транспортно-логистическую устранение этого противоречия приобретает для науки и практики особую актуальность. Ситуация усложняется необходимостью решения целого ряда разноплановых задач по совершенствованию технологии комплексного обслуживания клиентов на терминальнологистической инфраструктуре и по привлечению новых высокодоходных грузопотоков на терминальную сеть в совокупности.

Результаты исследования могут применяться транспортно-логистическими компаниями для решения целого спектра прикладных задач:

1) идентификации ЛО с учётом конструкции, вида складирования, размеров, технической оснащённости и др.;

2) выбора клиентом ЛО с учётом его функциональных возможностей и др.;

3) оценки проектов строительства и реконструкции объектов терминально-складской инфраструктуры железных дорог;

- МИР ТРАНСПОРТА, ТОМ 17 , № 4, С. 112-135 (2019) 
Таблица 1

\begin{tabular}{|c|c|}
\hline Результат & Возможная сфера использования \\
\hline $\begin{array}{l}\text { 1. Программный комплекс } \\
\text { «Классификация } \\
\text { логистических объектов» }\end{array}$ & $\begin{array}{l}\text { унификация терминологии и требований к логистическим объектам, } \\
\text { применимая и в практике сделок по складской недвижимости; } \\
\text { простота и удобство применения для транспортно-логистической } \\
\text { компании и клиента; } \\
\text { складская логистика, управление цепями поставок, управление } \\
\text { процессами перевозок через терминальную сеть, развитие терминально- } \\
\text { складской инфраструктуры. }\end{array}$ \\
\hline $\begin{array}{l}\text { 2. Программный комплекс } \\
\text { «Идентификация } \\
\text { и маркировка логистических } \\
\text { объектов» }\end{array}$ & $\begin{array}{l}\text { гибкие коммерческие предложения клиентам в концентрированной } \\
\text { и простой форме об объектах; } \\
\text { новый формат рекламной кампании услуг транспортно-логистического } \\
\text { холдинга; } \\
\text { упрощение взаимодействия участников процесса перевозок, } \\
\text { автоматизация присвоения универсальной нумерации и доступа к базе } \\
\text { данных терминально-складской инфраструктуры. }\end{array}$ \\
\hline $\begin{array}{l}\text { 3. Общая концепция } \\
\text { и архитектура } \\
\text { автоматизированной } \\
\text { системы управления } \\
\text { «Терминальная сеть» }\end{array}$ & $\begin{array}{l}\text { создание IT-платформы для подготовки выхода транспортно- } \\
\text { логистической компании на уровень логистического провайдера 4-5 PL; } \\
\text { создание единой общесетевой базы систематизированных данных } \\
\text { о работающих на сети железных дорог объектах терминально-складской } \\
\text { инфраструктуры (паспорта, номера, знаки); } \\
\text { совершенствование работы «в одно окно» по принципу } \\
\text { клиентоориентированности. }\end{array}$ \\
\hline $\begin{array}{l}\text { 4, 5. Проекты стандарта } \\
\text { и логистического } \\
\text { руководства }\end{array}$ & $\begin{array}{l}\text { стандартизация и унификация параметров терминально-складских } \\
\text { объектов, классификационного подхода и терминологического аппарата } \\
\text { в сегменте грузового бизнеса транспортно-логистической компании, } \\
\text { методическое обеспечение проектирования логистических объектов; } \\
\text { в дальнейшем - разработка эффективных программ стратегического } \\
\text { развития отрасли. }\end{array}$ \\
\hline
\end{tabular}

4) оценки логистической деятельности терминальной сети компании в целом;

5) контроля и аудита работы терминальной сети;

6) проектирования ЛО с оптимальными параметрами;

7) планирования работы железнодорожного транспорта, что обеспечит рост доходов от логистической деятельности в целом.

\section{КЛЮЧЕВЫЕ ВЫВОДЫ}

1. Эффективность изложенных предложений заключается в привлечении новых клиентов на железнодорожный транспорт, «переключении» с автомобильного транспорта потенциальных грузопотоков высокодоходных грузов за счёт гибких коммерческих предложений в максимально удобном, упрощённом виде, повышения их информативности. Применение предложений может быть реализовано при подготовке рекламных предложений и рассылке предложений клиентам. Это в полной мере «...повысит конкурентоспособность железнодорожного перевозчика на транспортнологистическом рынке» [1], а также позволит сформировать «единую клиентоориентированную информационную среду как основное условие для логистического провайдинга 4 и 5 уровня» [2, 3], к достижению которого сегодня стремятся многие железнодорожные компании.

2. Полученные результаты направлены на подготовку цифровой платформы и автоматизацию принятия решений по сквозному, комплексному управлению объектами терминальной сети. В свою очередь, это позволит расширить клиентскую базу и повысить эффективность работы логистического блока железнодорожных компаний. Это достигается за счёт упрощения взаимодействия с клиентами, предоставления информации о логистических объектах и услугах в сконцентрированном и адаптированном под интересы клиента формате. Такими новыми, клиентоориентированными, форматами подачи информации могут стать: «логистический класс» станции, «маркировочный знак» и «идентификационный номер» логистического объекта, а также «интерактивная цифровая платформа», обеспечивающая частичное раскрытие информации и активное участие клиентов.

3. Обзор потенциальных сфер применения полученных результатов сведён в таблицу 1. 


\section{ЛИТЕРАТУРА}

1. Транспортная стратегия РФ на период до 2030 г. Утв. распоряжением Правительства РФ 22.11.2008 г. № 1734-p. [Электронный pecypc]: http://doc.rzd.ru/ $\mathrm{doc} /$ public/ru?id=3771\&layer_id=5104\&STRUCTURE $\mathrm{ID}=704$. Доступ 17.01.2019.

2. Концепция создания терминально-логистических центров на территории РФ. - М., 2012. [Электронный ресурс]: http://cargo.rzd.ru/dbmm/ download? $\mathrm{vp}=5 \&$ load $=y \& c o l \_i d=121 \& i d=74208$. Доступ 17.01.2019.

3. Концепция реализации комплексного научнотехнического проекта «Цифровая железная дорога». [Электронный ресурc]: https://www.samgups.ru/units/ unir/Proekt\%20koncepcii\%20cifr.\%20dorogi.pdf. Доступ 17.01.2019.

4. Куренков П., Сафронова А., Кахриманова Д. Логистика международных интермодальных грузовых перевозок // Логистика. - 2018. - № 3. - С. 24-27.

5. Покровская О. Д. О терминологии объектов терминально-складской инфраструктуры // Мир транспорта. - 2018. - № 1. - С. 152-163.

6. Покровская О. Д. Классификация объектов железнодорожной терминально-складской инфраструктуры // Вестник УрГУПС. - 2017. - № 1. C. $70-83$.

7. Покровская О. Д., Маликов О. Б. Методика построения сетевого графа структуры логистического объекта // Мир транспорта. - 2017. - № 1. - С. 18-27.

8. Тарифное руководство № 1. Часть 1 (Правила применения тарифов). - Прейскурант № 10-01: Тарифы на перевозки грузов и услуги инфраструктуры, выполняемые РЖД. [Электронный ресурc]: http:// doc.rzd.ru/doc/public/ru\%3Fid\%3D6188 \%26layer id\%3D5104\%26STRUCTURE_ID\#4704738. Доступ 17.01.2019.

9. Тарифное руководство № 4 (ред. от 28.11 .2008 г., с изм. от 18.11.2010 г.). Книга 2. Часть 1. Алфавитный список железнодорожных станций.

10. Тарифное руководство № 4 (ред. от 28.11.2008 г., с изм. от 18.11.2010 г.). Книга 3. Тарифные расстояния между транзитными пунктами.

11. Инструкция по кодированию объектов станций, наименований грузоотправителей, грузополучателей и грузов на железных дорогах (утв. 15.05.1970 г. № ЦМ/2706, по сост. на авг. 2014).

12. Ермолаев К. Н., Афанасенко И. Д., Покровская О. Д. и др. Экономика России: прошлое, настоящее, будущее: Монография / Под общ. ред. Н. А. Адамова. - М.: ИТКОР, 2014. - 248 с.

13. Покровская О. Д. Логистическое руководство: математические основы терминалистики, маркировка, классификация и идентификация логистических объектов железнодорожного транспорта: Монография. - Казань: Бук, 2017. - 281 с.

14. Маликов О. Б. Перевозки и складирование товаров в цепях поставок. - М.: УМЦ по образованию на ж.д. транспорте, 2014. - 536 с.

15. Титова Т. С., Ахтямов Р. Г. Система управления техносферной безопасностью. - СПб.: ПГУПС, 2017. $-23 \mathrm{c}$

16. Титова Т. С. Методология комплексной оценки влияния новых технологий на геоэкологическую обстановку // Вестник Всероссийского научно-исследовательского института железнодорожного транспорта. - 2005. - № 5. - С. 2.

17. Котляренко А. Ф., Куренков П. В. Логистизация информационных технологий на транспортных стыках (в морских портах и погранпереходах) // Транспорт. Экспедирование и логистика. - 2002. № 3. - C. 11-22.
18. Котляренко А. Ф., Куренков П. В. Взаимодействие на транспортных стыках при внешнеторговых перевозках // Железнодорожный транспорт. - 2002. № 2. - C. 48-52.

19. Куренков П. В., Котляренко А. Ф. Взаимодействие грузовладельца с причастными подразделениями при экспортно-импортных железнодорожных перевозках через морские порты // Бюллетень транспортной информации. - 1997. № 6. - C. 34-38.

20. Покровская О. Д. «Сбитый прицел» клиентоориентированности // «РЖД-Партнер» . [Электронный pecypc]: https://www.rzd-partner.ru/ logistics/news/sbityi-pritsel - klientoorientirovannos ti-414174/. Доступ 20.06.2016.

21. Покровская О. Д., Маликов О. Б. Классификация, иерархия и идентификация объектов терминально-складской инфраструктуры // Транспорт: наука, техника, управление. - 2017. № 8. - C. 13-21.

22. Воскресенский И. В., Покровская О. Д. Алгоритмизация комплексного расчёта параметров терминальной сети региона // Транспорт Урала. 2011. - № 1. - С. 10-13.

23. Самуйлов В. М., Покровская О. Д., Воскресенская Т. П. Интеграция региональной терминально-логистической сети в международные транспортные коридоры // Инновационный транспорт. - 2013. - № 1. - С. 33-37.

24. Самуйлов В. М., Покровская О. Д. Практика и эффективность формирования транспортно-логистических кластеров // Вестник УрГУПС. - 2016. № 4. - C. $76-88$.

25. Pokrovskaya O. D. Chi terminelistica reale come una nuova direzione scientifica // Italian Science Review. 2016. - 1(34). - pp. 112-116.

26. Покровская О. Д., Коровяковский Е. К. Логистика терминалов: перспективное направление логистики // Известия ПГУПС. - 2015. - № 3. C. $155-164$.

27. Воскресенская Т. П., Покровская О. Д. Методика и алгоритмизация принятия решений по формированию терминальной сети в регионе // Вестник Уральского государственного университета путей сообщения. - 2010. - № 3. - С. 74-84.

28. Классификация, разработанная Международной консалтинговой компанией Knight Frank. [Электронный pecypc]: http://www.stroi-baza.ru/ articles/one.php?id=667. Доступ 17.01.2019.

29. Классификация складских объектов в табличной форме. [Электронный ресурc]: http://www. pro-sklad.com/articles/articles 268.html. Доступ 17.01.2019.

30. Корпоративные компетенции ОАО «РЖД». [Электронный pecypc]: http://www.pult.gudok.ru/ archive/detail.php? ID=899804. Доступ 17.01.2019.

31. Политика клиентоориентированности холдинга «РЖД» в области грузовых перевозок. - Утв. распоряжением ОАО «РЖД» от 26.07.2016 г. № 1489 р. [Электронный pecypc]: http://www.consultant.ru/law/ ref/ju_dict/ word/udovletvorennost_klienta/. Доступ 17.01.2019.

32. Покровская О. Д. Комплексная оценка транспортно-складских систем железнодорожного транспорта / Дис... док. техн. наук. - СПб.: ПГУПС, 2018. $377 \mathrm{c.}$

33. Цифровая Россия: новая реальность. [Электронный ресурc]: https://www.mckinsey.com/ / media/mckinsey/locations/europe $\% 20$ and $\% 20$ middle\%20east/russia/our\%20insights/digital\%20russia/ digital-russia-report.ashx. Доступ 17.01.2019. 